\title{
Kikuyu Language
}

National Cancer Institute

\section{Source}

National Cancer Institute. Kikuyu Language. NCI Thesaurus. Code C153978.

A Niger-Congo Bantu language spoken primarily by the Kikuyu people of Kenya. 